\title{
КРИПТОВАЛЮТА: ПРОГНОЗ РАЗВИТИЯ В УСЛОВИЯХ СОВРЕМЕННОГО ФИНАНСОВОГО РЫНКА
}

\author{
(c) 2018 Шайдуллина Венера Камилевна \\ директор Центра исследований и экспертиз \\ Департамента правового регулирования экономической деятельности \\ Финансовый университет при Правительстве Российской Федерации \\ 125993, г. Москва, Ленинградский пр-т, д. 49 \\ E-mail:VKShajdullina@fa.ru
}

Актуальность данного исследования обусловлена ростом популярности использования на финансовом рынке цифровых производных инструментов и криптовалюты. Различие подходов к регулированию криптовалюты, наличие правовых рисков ее использования, влияние на финансовый рынок и высокая волатильность - все это свидетельствует о необходимости исследования правовой и экономической природы криптовалюты. В данной статье рассматривается основное понятие биткоина как криптовалюты, описываются особенности проведения операций с помощью криптовалюты в блокчейне, а также рассматриваются подходу государств к регулированию этого сегмента рынка. Приводятся прогнозы относительно изменения курса биткоина в ближайшем будущем.

Ключевые слова: платежное средство, монета, финансовый рынок, криптовалюта, биткоин.

Криптовалюта - это система цифровых, виртуальных денег. По сути, криптовалюта представляет собой математический код. Свое название она получила потому, что при обращении виртуальных денег используются элементы криптографии (в частности, электронная подпись). Единица криптовалюты - coin (монета). Такие монеты полностью защищены от подделки и являются наиболее безопасным денежным средством при проведении разных операций. Главным отличием криптовалюты от реальных денег является способ возникновения в цифровой среде. Обычную валюту сначала нужно внести на счет, а криптовалюта изначально создается в сети Интернет. По сути, криптовалюту создают и выпускают сами пользователи. Процесс создания криптовалюты не предусматривает участия посредника (то есть банка). Существует несколько способов создания криптовалюты:

- майнинг (при использовании майнинга требуется наличие специальной платформы);

- ICO (система инвестирования, первичное размещение монет);

- форжинг (формирование новых блоков в уже существующих криптовалютах).

Обычно, разработчиками криптовалюты оговаривается ее верхний предел, то есть то максимальное количество монет, которое может быть выпущено. К примеру, максимальное количество монет биткоина составляет 21 млн. монет [1].
Совершаемые с криптовалютой операции (транзакции) происходят между пользователями без привлечения третьей стороны. Информация о совершаемых транзакциях общедоступна, в отличие от информации о пользователях. Считается, что криптовалютой обеспечивается анонимность. Следует отметить, что именно анонимность стала одной из главных причин использования цифровых денег, основанных на блокчейн-технологии. Данная технология представляет собой базу данных, которая распределена по миллионам компьютеров пользователей во всем мире. Запись и хранение данных при обращении криптовалюты происходит одновременно на всех устройствах. Этим гарантируется абсолютная открытость и прозрачность совершаемых операций.

С 2009 года блокчейн выступает в качестве преобразующей силы информационных технологий. По прогнозам некоторых специалистов, данная технология настолько же революционна, как и Интернет, который сравнительно недавно кардинально изменил все сферы общественной жизни. Блокчейн разрабатывался для записи операций, совершаемых с виртуальной валютой. Но в настоящее время функции блокчейна распространяются на множество финансовых операций в банковской и производственной сфере, в правительственных службах и на финансовом рынке. Тем не менее, возможности применения блокчейн до сих пор не изучены в полной мере. 
Первоначально блокчейн разрабатывался в связи с потребностью в наличии финансового посредника, способного обеспечить безопасность денежных операций (транзакций). Блокчейн является новым типом записи операций с виртуальной валютой, преобразующим каждую транзакцию в отдельный блок. Совокупностью блоков образуется цепочка в хронологическом порядке [2].

Сегодня наиболее популярной криптовалютой является биткоин, который функционирует по принципу блокчейна. Ключевые характеристики биткоина - защита от несанкционированного доступа, идентификация и децентрализация.

С момента своего появления в 2009 году блокчейн прошел три стадии развития: Блокчейн 1.0, 2.0 и 3.0. Блокчейн 1.0 распространялся только на торговлю виртуальной валютой. Блокчейн 2.0 для своей работы использовал гораздо большие объемы финансовых операций (интеллектуальную собственность, владение цифровыми активами и сами цифровые активы). К тому же, Блокчейн 2.0 представлял собой «умный» контракт, то есть цифровой протокол, автоматически проводящий ранее запланированные транзакции, без привлечения третьей стороны [1]. Возможности Блокчейн 3.0 расширились еще больше. Новая модель функционирует на базе «умного» контракта, хотя и представляет собой автономные, децентрализованные единицы. Новая самоуправляемая модель способна кардинально изменить правительственные системы администрирования, аттестационные службы, системы голосования и облачные хранилища.

По оценкам многих экспертов, в ближайшем будущем блокчейн сможет кардинально изменить экономическую сферу. Так, например, блокчейн может использоваться для сохранения конфиденциальных данных и проверки подлинности информации, участвующей в бизнес-процессах. Компании, благодаря применению блокчейн-технологии, получат возможность создания собственных информационных систем, с помощью которых осуществляются транзакции. Данные транзакции не обязательно должны включать только денежные переводы между двумя пользователями (компаниями). Они могут включать и потоки учетных данных компаний. Кроме того, технология блокчейн может использоваться в целях осуществления информационного контроля [3].
Криптовалюта, как фактор роста преступности в сети «Интернет»

Технология блокчейн, несмотря на все свои преимущества, имеет и некоторые недостатки. Применению технологии блокчейн могут препятствовать такие факторы, как сложности расширения использования блокчейн в бизнес-среде; техническая сложность решений; необходимость наличия значительных временных и финансовых ресурсов. Касательно организационной среды отметим, что прогнозируется увеличение потребности в регуляторах, четко понимающих функционирование системы блокчейн и ее влияние на бизнес-среду. Регуляторы должны будут контролировать проводимые транзакции в целях предотвращения возможных сбоев. Обмен валюты - неотъемлемая процедура в экономике биткоина, так как купить биткоин, не обменяв его, невозможно. Несмотря на наличие сайтов (например, bitcoinary.com и localbitcoins. com), предоставляющих пользователям возможность избежать обмена, объединяя получателей и плательщиков в одной географической зоне, объем транзакций на таких сайтах недостаточно большой для обналичивания крупных сумм. По мнению экспертов, сосредоточенность транзакций является серьезной проблемой для правонарушителей. Так, если вор попытается украсть 1000 биткоинов, то такая кража будет сразу же обнаружена в рамках сети биткоина. Так как адрес вора известен (поскольку валютообменные сайты заботятся о транспарентности), то он просто не сможет переслать биткоины реально существующему сайту-валютообменнику. Злоумышленник может попытаться использовать не один, а сразу несколько сервисов, чтобы скрыть источник денежных средств, однако такие сервисы не имеют возможности для вывода 1000 биткоинов. Также были проанализированы иные схемы мошенничества с целью сокрытия источника украденных денежных средств с применением блокчейн-пилинга (Peeling-chain) и реальные возможности для идентификации личности злоумышленника.

Наиболее известный и тщательно проанализированный адрес в истории биткоина - «1DkyBEKt5S2GDt-v7aQw6rQepAvnsRyHoYM», названный «шелковый путь». Этот адрес был активен с января по сентябрь 2012 года. С января на указанный адрес переводились внушительные суммы в биткоинах. В общей сложности, за 8 месяцев сумма средств составила 613,326 ВТС [2]. С 
августа 2012 года с указанного адреса осуществлялись частичные транзакции на различные адреса, которые уже к концу года опустошили все накопления. В связи с внушительным балансом и весомым положением (около 5\% всех генерируемых биткоинов) этот адрес привлек к себе внимание всего биткоин-сообщества. По мнению некоторых специалистов, указанный адрес принадлежит сообществу «шелкового пути» не полностью, а является всего лишь кошельком для совершения транзакций. По мнению других, данный адрес принадлежал пользователю с логином pirate@40, обвиненному в создании мошеннической схемы Ponzi Bitcoin Savings \& Trust (доверительное управление инвестициями), которая стала предметом судебного процесса, инициированного Комиссией по ценным бумагам (The United States Securities and Exchange Commission, SEC). По мнению экспертного сообщества, любое преступление в рамках биткоин-сети может быть отслежено, a участники идентифицированы. «Шелковый путь» является наиболее ярким примером такой «псевдоанонимности». Главной сложностью в идентификации преступников являются методы вычисления, многие из которых могут быть осуществлены только в ручном режиме, что требует немало времени.

\section{Проблемы регулирования оборота криптовалюты}

В связи со стремительным ростом популярности данной криптовалюты, правительства разных стран были вынуждены сформировать свое отношение к биткоину. Таким образом, во многих странах уже созданы нормативные правовые акты, которыми регулируется использование этой платежной системы. На современном этапе биткоин признан в качестве платежного средства многими государствами. Часть стран уже приняла законодательные акты, регулирующие обращение биткоина на своей территории. В настоящее время криптовалюта используется в качестве платежного средства в нескольких странах. Так, Правительством Японии был принят закон от 1 апреля 2017 года о придании биткоину статуса официального платежного средства. Также был утвержден ряд дополнительных законопроектов, которые поспособствуют интеграции криптовалюты в местную банковскую систему. Правительством Германии биткоин был признан средством взаиморасчета и единицей финансового учета. В настоящее время в Германии биткоин является одним из видов официальных денег. Причина такого решения заключается в том, что данная виртуальная валюта активно используется местными поставщиками услуг и товаров, однако в связи с отсутствием надлежащего правового регулирования ими не уплачивался подоходный налог в размере 25\%. После того, как был принят соответствующий закон, все транзакции с биткоином стали облагаться подоходным налогом. Соединенные Штаты также признали виртуальную валюту на законодательном уровне. Некоторые исследователи считают, что биткоин конкурирует с американским долларом. К примеру, если ранее весь нелегальный мировой бизнес пользовался наличными долларами, то с биткоином он стал более мобильным и менее контролируемым. Изъять доллары гораздо проще, чем биткоины. Но сможет ли данная криптовалюта полностью заменить доллар? Поскольку количество монет биткоина ограничено, что такая ситуация не представляется возможной. К тому же, учащающиеся атаки хакеров на биткоин говорят об отсутствии полной безопасности и надежности ее использования. Многие эксперты, учитывая инновацонность и удивительность биткоина, утверждают, что в ближайшей перспективе он не сможет заменить ни доллар, ни евро. Швейцарское правительство приравняло биткоин к иностранной валюте. Но не каждое государство относится к использованию биткоина положительно. Совершение операций с виртуальной валютой нередко используется для отмывания незаконного дохода и для ухода от уплаты налогов. В связи с этим, во многих государствах приняты законодательные акты, содержащие запрет на совершение операций с криптовалютой. К числу таких стран относятся: Вьетнам, Таиланд, Швеция, Индия, Исландия, Эквадор, Боливия, Бангладеш и Китай. Исходя из действующего законодательства конкретного государства, за совершение операций с виртуальной валютой в одних странах предусмотрен штраф, в других - наказание в виде лишения свобода на срок до двенадцати лет (Бангладеш). В Российской Федерации еще в 2016 году специалистами обсуждалась возможность введения наказания в виде лишения свободы до 7 лет за владение или использование биткоинов [7]. Однако в 2017 году взгляды правительства изменились. В прошлом году В.В. Путин дал распоряжении о необходимости принятия нормативных правовых 
актов, регулирующих оборот цифровой валюты [8]. Особое внимание было уделено следующим аспектам: регулирование ICO, регистрация и налогообложение майнеров криптовалют. В целом Правительство РФ положительно относится к майнингу криптовалют и к блокчейн-технологии. Популярность криптовалюты в России возрастает с каждым годом. Так, некоторые заведения общепита уже принимают оплату криптовалютой, а сетью ресторанов Burger King даже выпущена собственная криптовалюта - whoppercoin. Вместе с тем, некоторые представители органов власти РФ до сих пор высказывают опасения по поводу криптовалюты. Так, например, Э. Набиуллина, председатель Банка России, считает нецелесообразным использование виртуальной валюты как законного средства платежа. По ее словам, Банк России против частных денег в любой форме (виртуальной или материальной) [9]. Раньше Э. Набиуллина уже озвучивала сомнения по поводу того, что криптовалюта может выполнять функцию резервной валюты, и подчеркивала неоднозначное отношение к виртуальным валютам. Ею было сказано, что Банк России следит за развитием данного рынка и видит, что потребителей привлекают такие стороны биткоина, как низкие издержки, мобильность и оперативность. Это свидетельствует о востребованности развития данного направления финансового рынка. При этом Э. Набиуллина упоминает и о рисках, связанных с использованием криптовалюты. Среди основных рисков выделяются: отсутствие обеспечения; отсутствие юридически обязанных субъектов; спекулятивный характер операций с криптовалютами; наличие высокого риска потери стоимости [10].

По мнению некоторых специалистов, Россия взвешивает положительные и отрицательные стороны легализации и использования виртуальной валюты. Среди положительных аспектов особенно выделяется возможность преодоления при помощи криптовалюты отрицательного влияния экономических санкций. Среди отрицательных аспектов исследователи выделяют облегчение совершения незаконных операций (торговля наркотиками, деятельность крупных преступных группировок). По их мнению, виртуальная валюта, в случае ее легализации, позволит российским чиновникам совершать электронные денежные переводы, уклоняясь, тем самым, от санкций. Бывший работник ЦРу Джонсон М. в одном из своих выступлений ска- зал, что интерес русских к криптовалюте обусловлен многими причинами. В частности, введенные против России санкции подстегивают к поиску новых способов вывода денег из страны [11].

Китай демонстрирует неоднозначное отношение к криптовалюте. В прошлом году китайским правительством была создана правовая база, направленная на регулирование и частичный запрет деятельности в рамках блокчейн-системы. В октябре 2017 года в силу вступил Закон, которым были установлены нормы регулирования виртуальной валюты. Положения, закрепленные в «Общих принципах гражданского права КНР», определяют, что криптовалюта приобрела статус виртуальной собственности. В число запрещающих нормы вошли запреты на биржевую торговлю цифровыми валютами и на проведение кампаний ICO. При этом Правительство КНР не видит серьезной угрозы в использовании цифровой валюты и даже работает над созданием собственной национальной виртуальной валюты, которая будет находиться в ведении национального банка КНР. В настоящее время Китай - крупнейший биткоин-трейдер в мире (на юань приходится около 80 процентов транзакций). Кроме того, именно в Китае находится самая крупная майнинговая ферма. Исходя из вышесказанного, приходим к выводу, что и РФ, и Китай стремятся к созданию суверенных криптовалют. Выпуском виртуальной валюты будет заниматься Центральный банк. Таким образом, криптовалюта будет иметь такой же статус, как и национальная валюта. У такой ситуации имеются определенные плюсы: снижение затрат на управление денежной системой, ускорение платежей между организациями и частными лицами, государственный контроль совершаемых сделок в целях налогообложения.

\section{Прогнозы развития криптовалюты}

В настоящее время все вместе взятые криптовалюты составляют менее 0,1\% стоимости наличных денег и ценных бумаг. В ближайшие десять лет доля криптовалют увеличится, как минимум, до 1\%. В таком случае вложения в криптовалюты сейчас дадут 10-тикратный эффект. По некоторым прогнозам, криптовалюты могут захватить до 4\% объема наличных денег и ценных бумаг. В таком случае рост курса биткоина будет еще более существенным. При оценке перспектив биткоина используется несколько подходов. Одним из таких подходов является 
предположение о том, что биткоин поглощает спрос на золото. В соответствии с этой моделью, стоимость биткоина в 2022 году может составлять от 20 тыс. до 55 тыс. долларов США. В настоящее время рыночная стоимость золота превышает стоимость биткоина более чем в сто раз. При этом предложение золота постепенно увеличивается в связи с его интенсивной добычей, а предложение биткоина остается и будет оставаться стабильным в связи с ограничением в 21 млн. ВТС. По всей видимости, этим создается огромная нагрузка на биткоин, следствием которой может быть только дальнейший рост.

Еще один подход заключается в применении к курсу биткоина принципа закона Мура (эмпирическое наблюдение, впервые сделанное Г. Муром, в соответствии с которым, количество транзисторов, которые размещаются на кристалле интегральной схемы, каждые 24 часа удваивается). Академик Гарвардского университета Д. Порто выявил, что закон Мура применим и к курсу биткоина. При сохранении текущего положения, к февралю 2021 году цена одного биткоина будет составлять больше 100000 долларов США [12]. Мнения отечественных экспертов по поводу перспектив роста курса биткоина характеризуются большей сдержанностью. Автор данной статьи придерживается следующего мнения. Невозможность взломать систему блокчейн - одно из главных преимуществ пользования и владения биткоинами. Однако сама суть цифровой валюты как программного продукта и возможность оперировать ею только через Интернет уже несет некоторые риски. Известны случаи утраты владельцами биткоинов своих накоплений после внезапного отключения интернета или поломки системного блока. Еще один аргумент в защиту биткоина, по нашему мнению, заключается в том, что не относится ни к одному государству. Соответственно, правительства стран не могут оказывать влияния на курс биткоина. Подобная «независимость» биткоина, по нашему мнению, является следствием того, что она не обеспечена материальными ценностями. Это позволяет манипулировать с его курсом, так как ни одно государство не поне- сет за это ответственность. Установление курса биткоина осуществляется только на основании спроса на него. В большей части случаев, спрос диктуется повышенным интересом к данному необычному инструменту. Еще одним фактором является обилие информации о биткоине. Так, за последние три месяца 2017 года информация о постоянном росте курса биткоина была главной новостью во многих СМИ. Это привело к ажиотажному интересу и росту почти до 20 тыс. долларов США за ВТС.

Некоторые эксперты прогнозировали, что курс биткоина в начале 2018 года упадет. Собственно, это и произошло. В начале февраля курс биткоина опустился до 6766 долларов США. По утверждениям специалистов валютного рынка, такая волатильность курса была обусловлена спекулятивными операциями, которые поддерживались вербальной интервенцией. Еще одной особенностью биткоина является то, что его владельцами, как правило, являются разрозненные лица, так как финансовые институты ряда государств ограничены в операциях с цифровой валютой. Как показывает сложившаяся практика изучения применяемых в мире схем финансовых пирамид, в них обычно задействовано значительно число индивидуальных участников, не связанных между собой или с финансовыми учреждениями. Вместе с тем, каждый участник имеет возможность заработать, если вовремя совершит продажу или покупку. При этом львиную долю прибыли получают организаторы. В случае с биткоином нет достоверных данных о том, кто осуществляет руководство процессом (по мнению автора статьи, такая группа лиц или отдельный человек, несомненно существует).

В подведение итога проведенному исследованию отметим, что феномен криптовалюты продолжает оставаться не до конца изученным. Экспертами прогнозируется дальнейший рост популярности криптовалюты. Все чаще высказывается мнение, что криптовалюта сможет заменить реальные деньги. Но точного прогноза пока еще никто не дает. Имеются лишь мнения и догадки, которые со временем будут либо опровергнуты, либо подтверждены.

\section{Библиографический список}

1. Аллахвердиева Ф.Х., Ерохина Е.В. Биткоин - криптовалюта будущего или очередной «мыльный пузырь»? // Конкурентоспособность в глобальном мире: экономика, наука, технологии. 2018. № 2 (61). С. 6-9.

2. Барсукова А.А., Шамышева О.Н. Криптовалюта - деньги ХХІ века // Молодежная наука в развитии регионов. 2018. T. 1. C. 334-337. 
3. Гезалова А.М., Халтурина О.А. Криптовалюта - за или против? // Современные научные исследования и разработки. 2018. № 2 (19). С. 105-107.

4. ерасимов К.Б., Сухина П.В. Криптовалюта биткоин и её роль в экономике // Аллея науки. 2018. Т. 2 . № 1 (17). C. 166-171.

5. Грандонян К.А. Криптовалюта как объект правовой политики: современное состояние правового регулирования // Базис. 2018. № 1 (3). С. 19-22.

6. Жарина Н.А. Криптовалюта в России: современное состояние и перспективы развития // Социально-экономические и технические системы: исследование, проектирование, оптимизация. 2018. № 1 (77). С. 80-90.

7. Минфин детализировал наказание за биткоины в России. URL [Эл. ресурc] // URL: www.vestifinance.ru/ articles/60001 (дата обращения 7.02.2019).

8. Биткоин в законе: как в России отрегулируют криптовалюты и ICO [Эл. pecypc] // URL: www.rbc.ru/money/2 4/10/2017/59ef5def9a794713956b0b5d (дата обращения 7.02.2019).

9. ЦБ РФ выступил против легализации криптовалют в России [Эл. ресурс] // URL: www.ria.ru/ economy/20171005/1506246580.html (дата обращения 7.02.2019).

10. Биткоин не станет резервной валютой [Эл. ресурс] // URL: www.business-swiss.ch/2015/06/glava-tsb-rfbitkoin-rezervnoj-valyutoj (дата обращения 7.02.2019).

11. Россия обойдет западные санкциитропой биткоина.[Эл.ресурс]//URL:www.russian.rt.com/inotv/2017-08-09/ Eks-sotrudnik-CRU-Rossiya-obojdyot-zapadnie (дата обращения 7.02.2019).

12. Чос О.А. Блокчейн и криптовалюта в экономике Российской Федерации // Вектор экономики. 2018 . № 1 (19). C. 25 . 